\title{
EDITORIAL \\ ARE WE TO CONCERNED WITH THE TECHNICAL AND MEDICAL SIDE OF NURSING TO THE DETRIMENT OF CARING FOR THE PATIENT?
}

I was speaking to an elderly relative who was 77 the other day. Her husband who is also 77 was in hospital having investigations for anaemia of unknown origin. She said to me that all the investigations you could think of were being undertaken and she was very happy. She continued that she was upset because she felt he was not being cared for. I probed further and asked her what she meant and she gave me an example. He had been in hospital for 5 days and all he had had for his lunch everyday was a sandwich. He had not had a hot meal for the duration of his stay in hospital. This was because when the menu came round he was often confused and needed help with filling it in and this help was not given and because the menu came round early she was not there to supervise and make sure he had a hot meal.

I thought about what she said and it made me ashamed to be a nurse. I know it is not politically correct to discuss the caring side of nursing. In this technological age nurses are taking their role further and carrying out more medical roles, but is that not the point of taking on these roles that as nurses we can bring something unique to them. For the growth and development of nursing I think it is important that we take on these roles and by doing this it will blur the divisions between nurses and doctors and promote real teamwork and mutual respect. However this should not be to the detriment of caring for the patient.

In the perioperative arena where much of what we do is technical and task orientated there is still room for nursing. In the anaesthetic room I think one of the key skills is building a relationship with a patient in a very short time span and then identifying patients who want their hand held and those who do not. This is not rocket science, but appears to be lost in the fight to take on further roles and is not deemed important.

In the recovery area the same applies. Assessment of the patient's needs is of the utmost importance not only from the physiological perspective but also their psychological and social needs. I had my appendix out a few years ago and it was a traumatic time. Not only was I 11 weeks pregnant but I was due to get married on the day I had the appendicectomy. One of the most caring things that was done for me was giving me ice to suck and allowing my husband to come into the recovery area and sit with me. This not only fulfilled my needs but it also helped my husband because he saw I was all right and more to the point so was the baby. Obviously more was being done for me on a technical level but these were the two things I was aware of and they meant so much to me.

The conference this year was entitled 'Priorities for Practice' and covered wide ranging subjects. Whilst I know the technological aspect of the role of the perioperative practitioner is very important so is the caring side of this role. So what are your 'Priorities for Practice?'

Best wishes and have a good summer.

Melanie Oakley

Journal Editor 